\title{
Spherical near-field scanning at the Technical University of Denmark
}

Hansen, J. E.; Jensen, F.

Published in:

I E E E Transactions on Antennas and Propagation

Link to article, DOI:

$10.1109 / 8.1174$

Publication date:

1988

Document Version

Publisher's PDF, also known as Version of record

Link back to DTU Orbit

Citation (APA):

Hansen, J. E., \& Jensen, F. (1988). Spherical near-field scanning at the Technical University of Denmark. I E E E Transactions on Antennas and Propagation, 36(6), 734-739. https://doi.org/10.1109/8.1174

\section{General rights}

Copyright and moral rights for the publications made accessible in the public portal are retained by the authors and/or other copyright owners and it is a condition of accessing publications that users recognise and abide by the legal requirements associated with these rights.

- Users may download and print one copy of any publication from the public portal for the purpose of private study or research.

- You may not further distribute the material or use it for any profit-making activity or commercial gain

- You may freely distribute the URL identifying the publication in the public portal

If you believe that this document breaches copyright please contact us providing details, and we will remove access to the work immediately and investigate your claim. 


\title{
Spherical Near-Field Scanning at The Technical University of Denmark
}

\author{
JESPER E. HANSEN, ASSOCIATE MEMBER, IEEE, AND FRANK JENSEN, MEMber, IEEE
}

Invited Paper

\begin{abstract}
The early work (1969-1979) on spherical near-field antenna measurements at the Technical University of Denmark is outlined.
\end{abstract}

\section{INTRODUCTION}

$\mathrm{F}$ ROM ITS FOUNDING in 1828 by H. C. Oersted until about 1962, the Technical University of Denmark (TUD) was located in the central part of Copenhagen. Due to the lack of room for expansion in the city, an entirely new campus was built over the years 1962-1972 in Lyngby, some $10 \mathrm{~km}$ north of Copenhagen, on an old airfield. Here, ample space permitted the construction of special facilities in addition to the more standardized buildings for laboratories, lecture halls, and student dormitories.

One such facility established in connection with the building housing the Electromagnetics Institute, was the large anechoic chamber which was opened for measurements in 1967. The chamber, installed by Emerson and Cuming, Inc., in the U.S., was not originally foreseen for near-field measurements. It was primarily intended for the determination of antenna far fields and impedances and for the measurement of scattering cross sections of radar targets in the frequency range $50 \mathrm{MHz}-$ $50 \mathrm{GHz}$. In addition, the chamber was designed to serve as an EMC facility for the measurement of, for example, interference from ignition noise in vehicles. The latter application of the chamber was the background for the selection of its dimensions. The chamber is $12 \mathrm{~m}$ long, $10 \mathrm{~m}$ wide, and $8 \mathrm{~m}$ high (measured between the tips of the absorbers) and was at the time of its opening, the largest anechoic chamber in Europe. It is a curious fact that the largest object which has so far undergone test in the chamber is not an object for EMC-testing but rather a 6-m-long scale model of the German DFSKopernikus satellite which was measured in 1984 using the spherical near-field method (Fig. 1).

During the first years of its existence, the chamber was mainly employed in conventional far-field measurements of antenna patterns and radar cross sections. It also served as a laboratory for research, guided by J. Appel-Hansen, on measurement accuracy and the determination of anechoic chamber specifications [1]-[3].

With the acquiring, little by little, of automated equipment and computing facilities, the idea of embarking into a research

Manuscript received January 1988.

J. E. Hansen is with the Electromagnetics Institute, The Technical University of Denmark, Lyngby, Denmark.

F. Jensen is with TICRA, Kronprinsensgade 13, Copenhagen, Denmark. IEEE Log Number 8821097 program on near-field antenna measurements became obvious. The original inspiration to the work at TUD in this area is owed to E. V. Jull, now at the University of British Columbia, Canada, who had done some of the early work on near-field antenna theory and measurements in the late fifties [4] and who was visiting scientist at TUD for two periods in 19631965.

\section{The Spherical Near-Field Transmission Formula}

The first endeavor in the direction of near-field measurement was the thesis work by Jensen [5]. Starting from the work of Brown and Jull [4], Jensen studied the influence of measurement error in two-dimensional cylindrical near-field measurements. This part of the thesis was published separately at two conferences [6], [7]. More important, however, was his original derivation of the transmission formula for spherical near-field measurements with probe correction. This part of the thesis was published at the 1970 Antennas and Propagation Society (AP-S) International Symposium [8] and later, in a more complete form, in an article [9].

About the time of Jensen's derivation of the spherical transmission formula, the planar and cylindrical near-field methods were well understood. The spherical method was, in general, believed to be impractical due to its expected numerical difficulties [10].

The spherical near-field transmission formula quantifies the signal $w$ received by a probe antenna when an antenna under test is transmitting. With an assumed time dependence of $e^{-i \omega t}$, Jensen's formula takes the form

$$
\begin{aligned}
& w(A, \chi, \theta, \Phi)=\sum_{s=1}^{2} \sum_{n=1}^{N} \sum_{m=-n}^{n} \sum_{\mu=-1,1} \\
& \cdot Q_{s m n}\left[e^{i m \Phi} d_{\mu m}^{n}(\theta) e^{i \mu \chi}\right] P_{s \mu n}(\mathrm{kA})
\end{aligned}
$$

where

$$
P_{s \mu n}(\mathrm{kA})=\frac{1}{2} \sum_{\sigma=1}^{2} \sum_{\nu=1}^{\nu^{\prime m a x}} C_{\sigma \mu \nu}^{s n}(\mathrm{kA}) R_{\sigma \mu \nu} .
$$

In the above equations, the Eulerian angles $(\chi, \theta, \Phi)$ and the near-field measurement distance $A$ specify the probe coordinate system in relation to the test antenna coordinate system (see Fig. 2). The quantities $Q_{s m n}$ and $R_{\sigma \mu \nu}$ are the test antenna and probe spherical wave coefficients. The rotation coefficients $\left[e^{i m \Phi} d^{n}(\theta) e^{i \mu \chi}\right]$ and the translation coefficients $C^{s n}$ $(\mathrm{kA})$ are known from spherical wave theory [11], [12]. They 


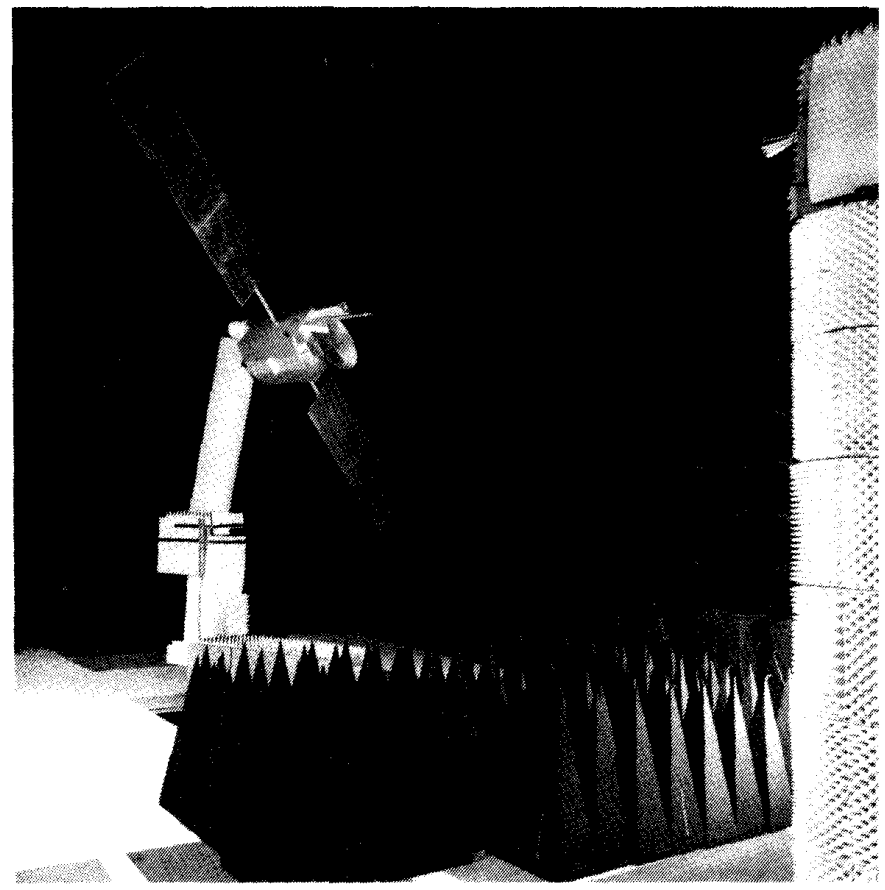

Fig. 1. Scale model $(1: 2.5)$ of DFS-Kopernikus communication satellite (MBB/ERNO) mounted for TM-TC antenna coverage measurement on TUD spherical near-field test range. Largest satellite dimension is 115 wavelengths.

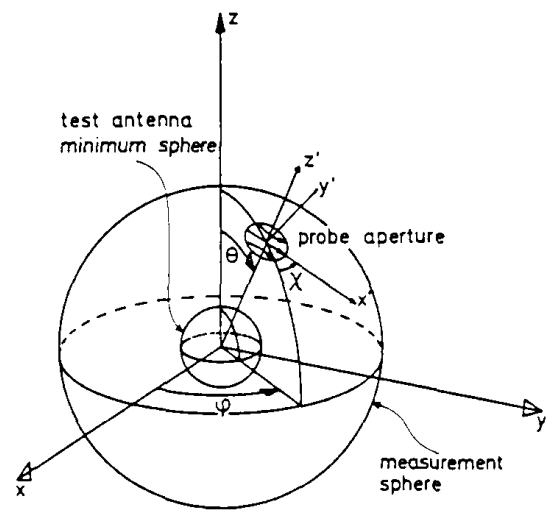

Fig. 2. Test antenna coordinate system $x y z$ and probe coordinate system $x^{\prime} y^{\prime} z^{\prime}$ in spherical near-field measurements. Measurement distance is distance between origins of two coordinate systems.

describe the coupling from spherical modes with indices $5 m n$ in the test antenna coordinate system to modes with indices $\sigma \mu \nu$ in the probe system. The maximum polar index $N$ in (1) is approximately equal to the wavenumber $k$ times the radius of the smallest sphere, the so-called minimum sphere, which could contain the test antenna.

During a spherical near-field scanning, the signal $w$ is measured in amplitude and phase on a sphere with radius $A$ at points spaced equidistantly in $\theta$ and $\Phi$, with two polarizations, corresponding to $\chi=0^{\circ}$ and $\chi=90^{\circ}$, applied at each point. From the measured data, all $Q_{s m n}$ can be found. This, however, requires a transformation algorithm for solving the transmission formula for the unknown test antenna coefficients, all other quantities being known.

The first step in solving (1) for the test antenna spherical wave coefficients $Q_{s m n}$ is to apply a Fourier transformation in the angular variables $\chi$ and $\Phi$. This yields

$$
\begin{aligned}
w_{\mu m}(A, \theta)=\sum_{s=1}^{2} \sum_{n=|m|}^{N} Q_{s m n} d_{\mu m}^{n}(\theta) P_{s \mu n}(\mathrm{kA}), & \\
& |m| \leq N, \quad \mu=-1,1 .
\end{aligned}
$$

The major obstacle in developing a practical transformation algorithm was to find a way of solving the transformed transmission formula (3) without expending excessive computer time. The direct brute-force method was obvious and consisted in obtaining as many data values of $w_{\mu m}$ as required to form from (3) a large system of linear equations in the unknown coefficients $Q_{s m n}$ for the test antenna. A procedure along this line, however, would at that time, even for a rather small test antenna, require several hours on the computer to solve for the coefficients. It would also have been difficult in general to select the data points without the sets of equations becoming ill-conditioned.

A solution to the problem was given by A. C. Ludwig, formerly of the Jet Propulsion Laboratory, Pasadena, CA, who was a Visiting Professor at TUD in 1972. Ludwig [13] suggested solving the large system of linear equations by an iterative technique based on the fact that, due to the orthogonality of the $d_{\mu m}^{n}(\theta)$ functions, the inverse matrix of the system can be approximated by the transposed matrix. 
Typically, four iterations eliminate the inaccuracy of the approximation. The computer time for Ludwig's iterative method is proportional to $N^{3}$ whereas direct solution requires a computer time proportional to $N^{4}$.

At the AP-S Symposium in Atlanta in 1974, we learned of the breakthrough made by P. Wacker at the National Bureau of Standards (NBS), Boulder, CO, who had devised an effective method of computing the coefficients $Q_{s m n}$ in (3). The Wacker algorithm [14] is based on solving (3) by applying the orthogonality of $d_{\mu m}^{n}(\theta)$ and solving the resulting integral in closed form by expanding $w_{\mu m}(\mathrm{~A}, \theta)$ and $d_{\mu m}^{n}(\theta) \sin \theta$ into Fourier series. Wacker also proposed the use of a probe antenna with only the azimuthal indices $\mu= \pm 1$.

In 1975, F. Holm Larsen, who had just started work on near-field testing at TUD, spent three weeks at NBS where he learned the details of the new algorithm published by Wacker for inverting Jensen's transmission formula and acquainted himself with a computer code under development by R. L. Lewis for the case without probe correction.

\section{The First Probe Corrected Spherical Near-Field Measurement}

With the clear trend in space communications to higher and higher frequencies, the European Space Agency (ESA) was increasingly aware of the problem of precision testing of advanced antenna systems for spacecraft. As an alternative to larger and larger outdoor far-field test ranges, near-field scanning methods seemed promising. A first study contract was awarded to Marconi Research Laboratory, England [15]. In 1975, TICRA, a small company in Copenhagen, signed a contract with ESA with the purpose of studying spherical nearfield testing in more detail, both theoretically and experimentally. Jensen, now with TICRA, was Project Manager, and it rested upon TUD, as a subcontractor, to provide measurement facilities in the anechoic chamber as well as engineering assistance. On the theoretical side, the two data reduction methods available, Ludwig's iterative scheme and the Wacker algorithm, were investigated. Ludwig's scheme turned out to require about twice as many measurement points as the Wacker algorithm and, furthermore, did not include probe correction [16]. The Wacker algorithm was therefore adopted and the first experiment was planned. A modified version of Lewis' computer code for computing the far fields was implemented.

The first measurement series was made in $X$ band using as the test antenna a dipole on a scale model of a cylindrical satellite with solar panels which had previously been used at TUD for the experimental verification of antenna pattern prediction by moment methods and geometrical theory of diffraction (GTD) [17], [18]. The measuring equipment used was a standard elevation over azimuth test antenna tower, an HP network analyzer as the receiver, and two different probes, i.e., an open circular waveguide and a 17-dB conical corrugated horn (Figs. 3 and 4). The measurements were made at approximately one tenth of the Rayleigh distance, and the computed far fields compared well with the true far field when the open waveguide was used as a probe. However, when the corrugated horn was applied, sidelobe levels were



Fig. 3. First probe corrected spherical near-field measurement. Geometry of measurement setup with 15.6-wavelength diameter satellite model as test object and horn probe.

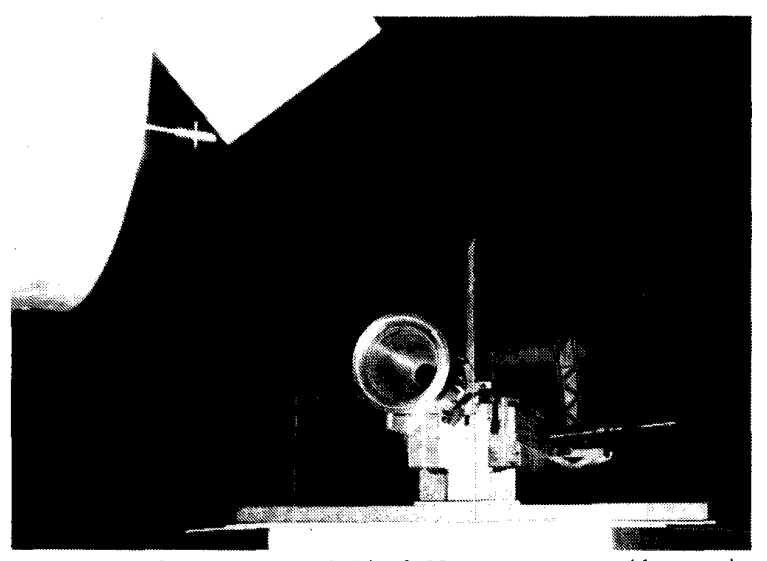

Fig. 4. Setup for measurement in Fig. 3. Note arrangement with two strings for changing probe polarization.

markedly off the correct value, thus suggesting the necessity for probe correction. In the second measurement series, a 36dB gain paraboloidal reflector antenna was measured. Here, the results for the computed far fields were in good agreement with known far-field diagrams. It was further shown that truncation of the spherical measurement surface could be done without serious reduction in the accuracy of the resultant far field. Included in the study was an investigation of measurement inaccuracies. The conclusion here was that the most severe error sources were receiver errors such as nonlinearity and drift and mechanical errors of the setup, especially angular resolution errors and nonintersection of the horizontal and vertical axes of the antenna positioner.

F. Holm Larsen, who had participated in the contract work, continued, as a part of his Ph.D. studies, to investigate the possibility of probe correcting the measurements made on the satellite model with the corrugated horn as the probe. Supported by the Danish Technical Research Council, an entirely new computer code was written [19], [20]. The code 


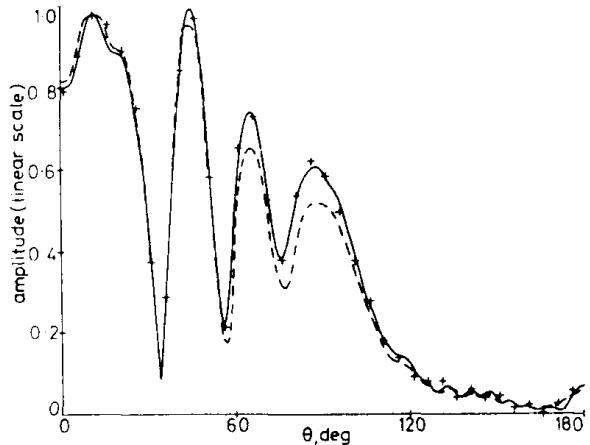

Fig. 5. Radiation patterns in cut $\Phi=90^{\circ}$ for satellite model in Figs. 3 and 4. Dashed line is far-field computed without probe correction. Full line is far-field computed with probe correction. Crosses indicate measured far field.

was based upon the ideas of Wacker [14], however, with important improvements. New recurrence relations were developed and implemented allowing the Fourier coefficients of $d_{\mu m}^{n}(\theta)$ (in the "delta pyramid") to be calculated in the same order as needed in the code. Thus considerable savings in computer storage and time were obtained. Other features were the introduction of a convenient convolution summation for increased speed and the introduction of the new concepts, the input probe and the output probe.

The new code was the first spherical transformation program with probe correction. It was designed to compute, from a given set of data measured with a specified (input) probe on a spherical surface in the test antenna near field, the signal that could be expected in an (output) probe scanning another spherical surface about the test antenna, e.g., the farfield sphere. Using the new code, Larsen recomputed the far fields from the near-field data taken with the directive probe on the satellite model and was able to demonstrate the influence and importance of probe correction in spherical near-field measurements [21] (Fig. 5).

\section{TUD-ESA Joint Effort on Spherical Near-Field Testing}

In the fall of 1976, ESA took steps toward defining its policy with respect to spacecraft antenna testing. As a consequence hereof, it was decided to promote the state of the art further by carrying out the development of an experimental spherical near-field test facility. By using this facility in a series of experimental programs, it was the plan to study all aspects of the spherical method relevant to satellite antenna applications. Further, it was intended to acquire all technical experience, including processing software and special test equipment, for definition and design of an operational facility.

A contract between ESA and TUD, with TICRA as a subcontractor, was signed in the spring of 1977. The contract covered the first phase of an overall joint effort development plan in four phases. The first phase essentially covered system specification work, tolerance studies, and critical software developments. A considerable amount of time was spent in defining and planning the detailed work of the next phases [22]. The project managers for TUD were H. Bach and J. E. Hansen, while Jensen guided the work on behalf of TICRA.

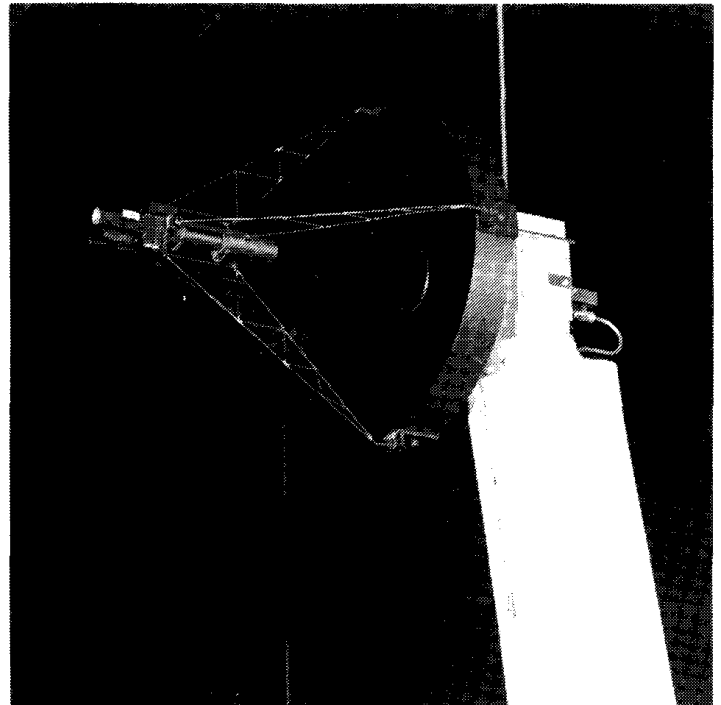

Fig. 6. OTS Eurobeam antenna (Selenia SpA) mounted for spherical nearfield testing in TUD anechoic chamber.

In the second phase, which began in February 1978, the work was expanded considerably. Purchases of hardware were made and the design and construction of a new high precision elevation over azimuth positioner was made by the TUD Department of Mechanical Engineering. The positioner was installed in the anechoic chamber, and the probe was mounted on a tower which in turn was mounted on a moveable cart so that the radius of the measurement sphere could be varied. The probe tower also served as a convenient support for the important alignment tool, a one arcsecond theodolite.

Several novel concepts in near-field testing were incorporated in the facility. One of these was the dual channel circuit for the simultaneous measurement of two orthogonal polarizations [23]. This was made possible by using a three-channel receiver developed for the project by Scientific Atlanta, Inc. A special operating system permitting concurrent operations was developed for the microcomputer controlling the positioning of the tower and the collecting of all RF data. The data processing software consisted of two packages. The first was Larsen's transformation algorithm which in its first version permitted a maximum test antenna diameter of $80 \lambda$. The second software package was a facility simulator with a series of input and output modules for simulation of mechanical inaccuracies and receiver inaccuracies for spherical near-field test setups.

The final report [24] was in eight volumes and served as the detailed documentation for all subsystems of the developed experimental, spherical near-field facility in the TUD anechoic chamber. Calibrations and test runs carried out in April 1979 were made at $11.7 \mathrm{GHz}$ with a 20 -wavelength reflector antenna (the "Eurobeam" antenna for the OTS satellite (Fig. 6)) made by Selenia, Rome, Italy, as the test object. The agreement between the far fields obtained by probe corrected transformations from two different and independent sets of near-field data taken at the distances of $100 \lambda$ and $200 \lambda$ were 

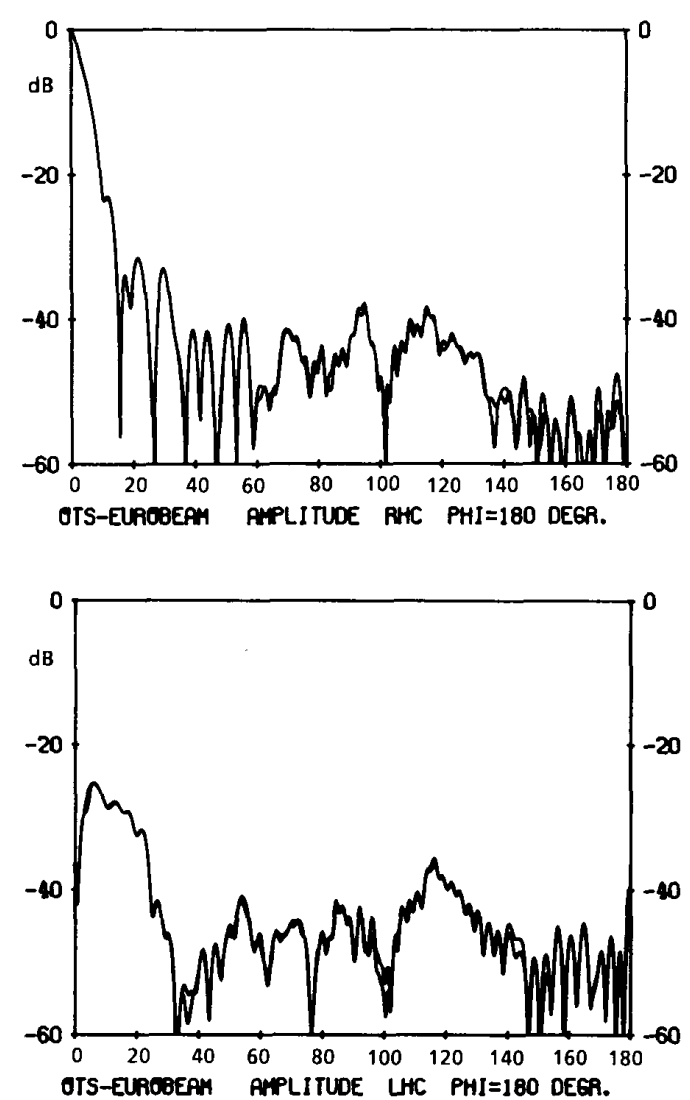

Fig. 7. Copolar (RHC) and cross-polar (LHC) radiation patterns for Eurobeam antenna in Fig. 6. Note that on each diagram two curves are superimposed corresponding to measurement distances of $1 / 4$ and $1 / 8$ Rayleigh distance, respectively.

extremely encouraging (Fig. 7). A summary of the work of the first two phases of the TUD-ESA joint effort on spherical near-field testing is presented in [25].

\section{CONCLUSION}

The above account of research done at the Technical University of Denmark within spherical near-field testing covers the work of the first ten years, i.e., from 1969 to 1979. Since then our efforts in the area have continued. An expanded version, completed under the last phases of the TUD-ESA joint effort, of the test range is described in [26]. The facility is in extensive use for research, measurement of antennas for space applications and precision calibration of standard gain horn antennas, in the frequency range $3-40 \mathrm{GHz}$. A comprehensive treatment of spherical near-field antenna testing, based upon the experiences and developments over the years at TUD and TICRA, is presented in a recent monograph [12].

\section{REFERENCES}

[1] J. Appel-Hansen, "Support scattering effects on low-gain satellite antenna pattern measurements," IEEE Trans. Antennas Propagat., vol. AP-21, pp. 370-371, May 1973.

[2] ___, "Reflectivity level of radio anechoic chambers," Special Issue on Antenna Measurements, IEEE Trans. Antennas Propagat., vol. AP-21, pp. 490-498, July 1973.
[3] - "Precision measurement of backscattering cross-sections as a function of frequency," IEEE Trans. Instrum. Meas., vol. IM-25, pp. 363-370, Dec. 1976.

[4] J. Brown and E. V. Jull, "The prediction of aerial radiation patterns from near-field measurements,' Proc. Inst. Elec. Eng., vol. 108, part B, no. 42, pp. 635-644, Nov. 1961 .

[5] F. Jensen, "Electromagnetic near-field-far-field correlations," Ph.D. dissertation, Electromagnetics Inst., Technical Univ. Denmark, report LD 15, July 1970.

[6] _-, "The influence of inaccuracies of measurements on antenn near-field-far-field correlation," Proc. 4th Collo. Microwave Communication, vol. 3, Budapest, Hungary, Apr. 1970, pp. ET13/1-10.

[7] _... "Methods of determining far-field data from near-field measurements," in Int. Symp. Electromagnetic Wave Theory (preprint), Tblisi, USSR, Sept. 1971, pp. 541-550.

[8] J. E. Hansen and F. Jensen, "Near-field measurements using directive antennas," in Int. IEEE/G-AP Symp. Digest, pp. 284-287, Columbus, OH, Sept. 1970.

[9] F. Jensen, "On the probe compensation for near-field measurements on a sphere," Arch. Elek. Übertragung., vol. 29 , no. $7 / 8$, pp. 306-308, July/Aug. 1975.

[10] D. T. Paris, W. M. Leach, Jr., and E. B. Joy, "Basic theory of probecompensated near-field measurements," IEEE Trans. Antennas Propagat., vol. AP-26, pp. 373-379, May 1978

[11] A. R. Edmonds, Angular Momentum in Quantum Mechanics, 2nd ed. Princeton, NJ: Princeton Univ. Press, 1974

[12] J. E. Hansen, Ed., Spherical Near-Field Antenna Measurements London: Peter Peregrinus, 1988.

[13] A. C. Ludwig, "Calculation of orthogonal-function expansions from imperfect data," Electromagnetics Institute, Technical Univ. of Denmark, Rep. R 102, 1972. 
[14] P. F. Wacker, "Non-planar near-field measurements: Spherical scanning," Electromagnetics Div., Nat. Bureau of Standards, Boulder, CO. Rep. NBSIR 75-809, June 1975.

[15] R. W. Ashton, K. Jolly, P. J. Wood, and B. Claydon, "A study of the prediction of antenna performances from near field measurements,' Marconi Res. Lab., Chelmsford, England, Marconi Tech. Rep. MTR 75/43, Final Rep., ESTEC Contract 2239/75/HP, June 1975.

[16] F. Jensen and F. Holm Larsen, "Spherical near-field/far-field techniques," in Proc. 6th European Microwave Conf., Rome, ltaly, Sept. 14-17, 1976, pp. 98-102.

[17] N. C. Albertsen, J. E. Hansen, and N. E. Jensen, "Computation of radiation from wire antennas on conducting bodies," IEEE Trans. Antennas Propagat., vol. AP-22, pp. 200-206, Mar. 1974.

18] H. Bach et al., "A study on radiation pattern prediction for high frequency satellite antennas," Electromagnetics Inst., Technical Univ. of Denmark, Rep. R 145, Final Rep. ESTEC Contract 2290/74, Oct. 1975.

[19] F. H. Larsen, SNIFTC: Spherical Near-Field Transformation Program with Probe Correction, Electromagnetics Inst., Technical Univ. Denmark, Rep. R 201, Oct. 1978.

[20] - , "Probe-corrected spherical near-field antenna measurements," Ph.D. dissertation, Electromagnetics Inst., Technical Univ. Denmark, Rep. LD 36, Dec. 1980

[21] _-, "Probe correction of spherical near-field measurements," Electron. Lett., vol. 13, pp. 393-395, July 1977.

[22] H. Bach et al., "Study and development of near-field test methods for antennas," Electromagnetics Inst., Technical Univ. Denmark, Rep. R 194, Final Rep., ESTEC Contract 2955/76, Jan. 1978

[23] F. H. Larsen and J. E. Hansen, "A dual-polarized probe system for near-field measurements," in IEEE AP-S Symp, Digest, Seattle, WA, June 1979 , pp. $557-560$.

[24] H. Bach et al., "Facility design and test runs. Experimental spherica near-field antenna test facility," Electromagnetics Inst., Technical Univ. Denmark, Rep. R 208, Final Rep., vol. I (Executive Summary), ESTEC Contract 3337/77, Apr. 1979.
[25] J. E. Hansen, "Spherical near-field testing of spacecraft." ESA J, vol. 4, pp. 89-102, Apr. 1980

[26] "The TUD-ESA spherical near-field antenna test facility, Lyngby, Denmark," ESA Publication BR-19. ESA, Paris, France, Apr. 1984.

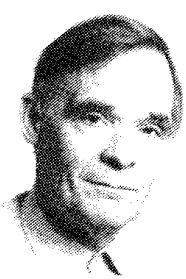

Jesper E. Hansen (A'62) was born in Frederiksberg, Denmark, in 1929. He received the M.Sc. and $\mathrm{Ph} . \mathrm{D}$. degrees in electrical engineering from The Technical University of Denmark in 1957 and 1965. respectively.

Since 1966 he has been an Associate Professor and Head of the Antenna Group at Electromagnetics Institute, TUD. He has been project manager for a number of research projects carried out for the European Space Agency within the area of spacecraft antennas. He is Editor of Spherical Near Field Antenna Measurements (Peter Peregrinus, 1988).

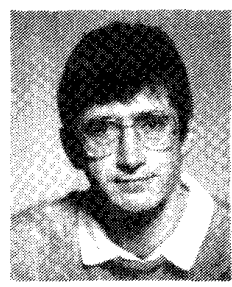

Frank Jensen ( $S^{\prime} 69-M^{\prime} 72$ ) was born in Copenhagen, Denmark, in 1943. He received the M.Sc. and $\mathrm{Ph} . \mathrm{D}$. degrees in electrical engineering from The Technical University of Denmark in 1968 and 1971. respectively

Since 1972 he has been with TICRA. Copenha gen, where he works in the field of numerical methods for electromagnetic problems. He has special experience within near-field measurement techniques, design, and construction of dual polarized high precision measurement probes and interaction between satellite antennas and the structures on which they are mounted. 